\title{
ADDITIONAL ACKNOWLEDGMENTS
}

We regret that the following special consultants were missed in our listing in the December issue. Their help during the past year is gratefully acknowledged.

\section{Robert Fish, Stanford University}

B. Wooten, Brown University

\section{ANNOUNCEMENT \\ Symposium on Aging and Human Visual Function \\ Washington, D.C. \\ March 31 - April 1, 1980}

The objective of this conference, sponsored by the National Academy of SciencesNational Research Council Committee on Vision, is to draw together what is known and point out how much is not known about basic changes in human vision that occur with age. It will provide vision scientists an opportunity to become better acquainted with gerontological issues and will delineate needs and problems for doing good research in this field. Topics discussed will include: General considerations (demographic aspects, methodological concerns, concepts of aging, disease vs. normal change); Ocular changes; Changes in visual functions; Perceptual changes; Neurological and circulatory aspects; and Human factors (quality of life, environmental design, compensatory approaches).

For further information, please contact:

Key Dismukes

Study Director

Committee on Vision

NAS-NRC

2101 Constitution Avenue, N.W.

Washington, D.C. 20418

(202) 389-6505 